\title{
La saga des oncogènes...
}

\section{* GLOSS AIRE*}

Transfection: transfert d'un fragment d'ADN dans une cellule étrangère.

Syngénique : d'une même lignée, génétiquement identique. Ici, portant les mêmes antigènes $d u$ CMH.

Allogénique : d'une même espèce mais d'une lignée différente. Ici, non identique pour les antigènes du CMH.

1. Bernards R, Schricr PI, Houwcling A, Bos J I., van der Eb A J. Tumorigenicity of cells transformed by adenovirus type 12 by evasion of T-cell immunity. Nature 1983; 305: 776-9.

2. Schrier PI, Bernards R, Vacssen RTM J, Houweling A, van der Eb A J. Expression of class I major histocompatibility antigens switched of by highly oncogenic adenovirus 12 in transformed rat cells. Nature $1983 ; 305: 771-5$

3. Borrelli E, Hen R, Chambon P. Adenovirus-2 $E_{1}$ A products repress enhancer-induced stimulation of transcription. Nature $1984 ; 312: 608-12$.

4. Guilfoyle RA, Osheroff WP, Rossini M. Two functions encoded by adenovirus early region $1 \mathrm{~A}$ are responsible for the activation and repression of the DNA-binding protein genc. Embv 7 1985; 4: 707-13.

5. Velcich A, Ziff E. Adenovirus E1A proteins repress transcription from the $\mathrm{SV}_{40}$ early promoter. Cell 1985; $40:$ 705-16.

6. Tanaka K, Isselbacher KJ, Khoury G, Jay G. Reversal of oncogenesis by the expression of a major histocompatibility complex class I gene. Science 1985; $228: 26-30$.

7. Wallich $R$, Bulbuc $N$, Hämmerling $G J$, Katzav S, Segal S, Feldman M. Abrogation of metastatic propertics of tumour cells by de novo expression of $\mathrm{H}-2 \mathrm{~K}$ antigens following $\mathrm{H}-2$ gene transfection. Nature 1985; 315:301-5.

8. Mougneau E, Glaichenhaus N, Cuzin F. Analyse génćtique des ćtapes précoces de la progression tumoralc. Médecine-Sciences $1985 ; 1: 86-90$.

9. Bernstein SC, Weinberg RA. Fxpression of the metastatic phenotype in cells transfected with human metastatic tumor DNA. Proc Natl Acad Si USA $1985 ; 82: 1726-30$

10. Kahn A. La saga des oncogènes. MédecineSciences 1985; $1: 10-1$.



armi le flot ininterrompu d'articles consacrés aux mécanismes de la cancérogenèse et aux oncogènes, certains sont de première importance par ce qu'ils apportent à notre conception des processus responsables de la cancérisation, de la tumorigénèse et de son développement in vivo. Par exemple, comment s'y prend la cellule tumorale pour échapper aux mécanismes de défense immunitaire?

Il est bien connu que les antigènes du complexe majeur d'histocompatibilité $(\mathrm{CMH})$ sont indispensables à la présentation aux lymphocytes $\mathrm{T}$ cytotoxiques de cellules portant sur leur membrane des antigènes étrangers. En d'autres termes, l'élimination d'une cellule tumorale portant à sa surface un antigène viral ou tumoral requiert que cette cellule exprime également des antigènes du $\mathrm{CMH}$ identiques à ceux des lymphocytes $\mathrm{T}$. Or, de très nombreuses cellules cancéreuses n'expriment que peu ou pas ces antigènes. Par exemple, la différence majeure entre les cellules infectées par laadénovirus 5 ( $\mathrm{ad} 5$, peu tumorigène) et l'adénovirus 12 (ad 12, très tumorigène), réside en l'absence, dans ces dernières cellules, des antigènes de classe 1 du $\mathrm{CMH}[1,2]$. Le mécanisme de cette inactivation pourrait être l'aptitude des protéines $\mathrm{E}_{1} \mathrm{~A}$, codées par un gène à expression très précoce du virus, à inactiver certains " enhancers ", bloquant donc la transcription du gène correspondant $[3,4,5]$. La responsabilité du blocage de l'expression des antigènes de classe 1 du CMH dans la tumorigénicité d'ad 12 vient d'être spectaculairement confirmée par Tanaka et coll. [6] et par Wallich et coll. [7]. Lorsque des cellules transformées par cette souche d'adénovirus sont "transfectées" "* par un gène cloné commandant l'expression d'un antigène du $\mathrm{CMH}$, elles perdent leur pouvoir tumorigène aussi bien chez un animal syngénique* qu'allogénique*.

Les interférons stimulent l'expression des antigènes du $\mathrm{CMH}$... et répriment celle de nombreux oncogènes, cette double action pouvant par conséquent constituer la base de leur activité antitumorale.

Une troisième classe d'oncogènes gouverne-t-elle l'acquisition par les cellules cancéreuses de leur potentiel métastatique?

De nombreux articles de médecine/sciences ont indiqué que la cancérisation était un processus à étapes, les étapes d'immortalisation et de transformation ayant été particulièrement bien discutées par François Cuzin et son équipe [8]. Très récemment Berstein et Weinberg viennent de démontrer qu'une troisième étape pouvait être individualisée dans la progression tumorale, et qu'elle était peut-être sous le contrôle d'une troisième classe d'oncogènes [9].

Des cellules de souris transfectées par de l'ADN contenant l'oncogène $\mathrm{Ha}-$ ras activé acquièrent un phénotype transformé et, inoculées à l'animal, entraînent la formation de fibrosarcomes non métastatiques. Lorsque ces mêmes cellules, déjà transformées par Ha-ras, sont sur-transfectées par l'ADN provenant d'une tumeur humaine métastasiante, certaines d'entre elles deviennent elles-mêmes capables d'entraîner la formation de nombreuses métastases chez l'animal. Une séquence particulière d'ADN humain, qui ne correspond pas à un oncogène connu, est associée à cette nouvelle propriété. Ainsi apparaît-il que le développement d'une tumeur invasive est la conséquence d'événements multiples et successifs sous le contrôle de mọdifications génétiques différentes. Les premières induisent "l'immortalisation", qui prédispose à la transformation en cellules transformées non invasives, sous l'effet d'un deuxième type de modifications; un troisième événement confërerait à ces dernières cellules leur malignité accrue et leurs propriétés de dissémination. Cette dernière étape pourrait impliquer des amplifications d'oncogènes connus (tels c-myc et $\mathrm{N}$-ras [10]) ou l'activation d'un troisième type d'oncogènes.

A.K. 